\title{
INVESTIGATION OF COOLANTS IN MACHINING OF TITANIUM ALUMINIDES
}

\author{
Daniel Finkeldei; Friedrich Bleicher
}

Vienna University of Technology, Getreidemarkt 9, 1050 Vienna, Austria

\begin{abstract}
Titanium and nickel based alloys are two types of industrially used materials. Especially in aerospace and automotive industry, the intermetallic titanium aluminides tend to replace these prevailing materials. Their density is only a half of nickel based alloys and a high strength at room temperature and hot condition is retained. But the high reaction affinity against tool materials, their low Youngs modulus and low heat conductivity cause difficulties in machining. During the machining process, low heat conductivity leads to high thermal loading of tools and therefore a well-directed cooling strategy is necessary. In this paper an overview about different cooling strategies, such as cryogenic carbon dioxide cooling and minimum quantity lubrication of the titanium aluminide $\mathrm{Ti}-48 \mathrm{Al}-2 \mathrm{Cr}-2 \mathrm{Nb}$ is shown. Based on a literature research and the experiments conducted in this investigation, cryogenic cooling is a reliable option for reducing toolwear.
\end{abstract}

Keyword: machining; outside diameter turning; titanium aluminide; cryogenic carbon dioxide cooling; minimum quantity lubrication
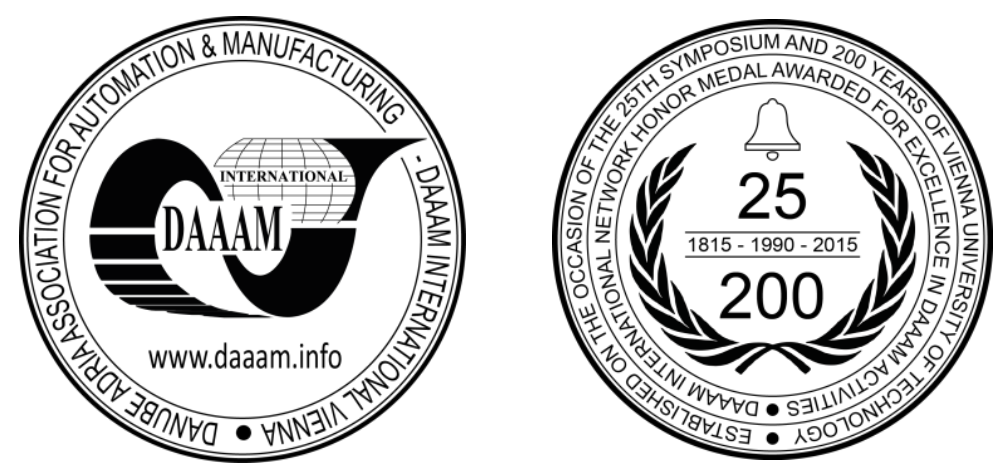

This Publication has to be referred as: Finkeldei, D[aniel] \& Bleicher, F[riedrich] (2016). Investigation of Coolants in Machining of Titanium Aluminides, Proceedings of the 26th DAAAM International Symposium, pp.0825-0833, B. Katalinic (Ed.), Published by DAAAM International, ISBN 978-3-902734-07-5, ISSN 1726-9679, Vienna, Austria DOI:10.2507/26th.daaam.proceedings.115 


\section{Introduction}

In applications of the automotive and aerospace industry, there is a high demand for materials with high strength properties in hot temperature conditions. Especially in supercharger engines and gas turbines, titanium and nickel based alloys are mainly used. The automotive manufacturer Mitsubishi constructed the first supercharger engine, for their model Lancer, with turbine blades entirely made out of a titanium alloy [1] benefiting from the advantage of a lightweight material, combined with high strength. The same situation is found in constructions of gas turbines. During the progression through the different compression stages, the temperature inside the gas turbine increases rapidly [2]. Inside the low-pressure compressor, temperatures up to 400 to $600^{\circ} \mathrm{C}$ are measured [2]. In these stages, titanium alloys like $\alpha-,(\alpha+\beta)$ - or $\beta$-alloys have established themselves successfully. But in the latest developments in engine models, researchers and manufacturers presented the potential of high-strength titanium aluminides to substitute the "normal" titanium alloys [3-5]. Furthermore, the lower weight reduced the total weight of the gas turbines significantly. This combination of low weight and high strength in warm and hot temperature conditions led to new research concepts. Material scientists constantly develop new titanium aluminide alloys, which retain their high strength in hot conditions. A TNM titanium aluminide was alloyed with 0.2at.\% lanthanum [5]. With this particular new titanium alloy, the flow stress was raised to $650 \mathrm{MPa}$ at temperatures of $900^{\circ} \mathrm{C}$. It shows the direction for developments in gas turbines. The goal is to substitute nickel based alloys in the high-pressure turbine section, where temperatures of at least $900^{\circ} \mathrm{C}$ are prevailing $[2,6]$. At the moment, nickel based alloys are the only materials, which can be used for these turbine blades, as they keep their high strength at such elevated temperatures [7].

A challenging problem of these materials is their machinability. Because of their high strength, high brittleness and low thermal conductivity, tool wear increases rapidly [8]. Another issue is the high chemical affinity [9, 10] to alternative tool substrates, like cubic boron nitride $(\mathrm{CBN})$ or ceramics. At present, tungsten carbides are the best developed tool materials for processing all titanium alloys; and they are used in industrial production processes [11]. Whilst titanium and nickel based alloys have been investigated in a very profound way in the past [i.e. 12-15], research for titanium aluminides intensified only one decade ago [i.e. 16-18, 26, 30]. At the moment, most of research is based on the machining technology of the outside diameter turning or milling to study the machining process. In the last years, there are a few research based on drilling and other machining techniques $[19,20]$. The main part of the investigations is the reduction of cracking and pullout during machining. Mantle and Aspinwall [21] found out, that cracking is mainly influenced by the depth of cut, whereas cutting speed and coolant supply have no significant effect. Sharman et al. [22] discovered a higher affinity to cracking, when machining with higher depth of cut. In another study, Hood et al [23] explained that the grain size of the microstructure has a significant influence on material defects.

Other studies [24, 25] compared the machining processes directly. Settineri et al. [26] analyzed three different titanium aluminides in turning and milling processes. Tool wear, workpiece roughness and surface finish were evaluated. In order to minimize cutting fluid during the machining of the titanium aluminide Ti-48Al-2Cr-2Nb, Priarone et al. [27] investigated several flow rates for minimum quantity lubrication (MQL).

At present, there is no investigation about the influence of the cross section of a chip on the machinability of $\gamma$ $\mathrm{TiAl}$ found in the literature. It is interesting, which component of the cross section of a chip has a significant effect on tool life reduction. The cross section of a chip is affected by the feed rate and the depth of cut. For the following survey, the implemented investigation strategy for obtaining a constant removal rate, is an increase of the feed rate and a decrease of the depth of cut or vice versa. Furthermore, tool wear and cutting forces are measured and analyzed.

\section{Experimental setup}

Machining tests were performed in a facing process on a CNC lathe machine HEID FS300. The workpiece material was a Ti-48Al-2Cr-2Nb titanium aluminide. The ultimate tensile strength is $442 \mathrm{MPa}$ and the yield strength is $324 \mathrm{MPa}$ with a hardness of $295 \mathrm{HV}_{100}$. With a maximum axial path 1 of $9 \mathrm{~mm}$, the workpiece was cut out up to a diameter of $160 \mathrm{~mm}$. The external diameter of the disk material varied between 220 and $225 \mathrm{~mm}$. The cutting speed was fixed to $40 \mathrm{~m} / \mathrm{min}$. To validate the cutting behavior, the feed rate $\mathrm{f}$ and depth of cut $\mathrm{a}_{\mathrm{p}}$ were adjusted in two parameter setups. On the one hand, a feed rate of $\mathrm{f}=0.05 \mathrm{~mm}$ and a depth of cut $\mathrm{a}_{\mathrm{p}}=0.8 \mathrm{~mm}$ were applied and on the other hand a feed rate $f=0.075 \mathrm{~mm}$ and a depth of cut $a_{p}=0.5 \mathrm{~mm}$ were set (see Error! Reference source not found.). In this way, the chip thickness remained at a constant value. During the experiments, tool wear and cutting forces were measured. Tool wear was evaluated using a Keyence VW600C microscope with a magnification factor of up to 200 (Fig.1 down right). Cutting forces were measured by a 3-component dynamometer Kistler 9129AA. It was mounted between the tool holder and the VDI shank. To filter the signal noise, a Savitzky-Golay-Filter with a polynomial order of 12 and 3500 side points was applied. 


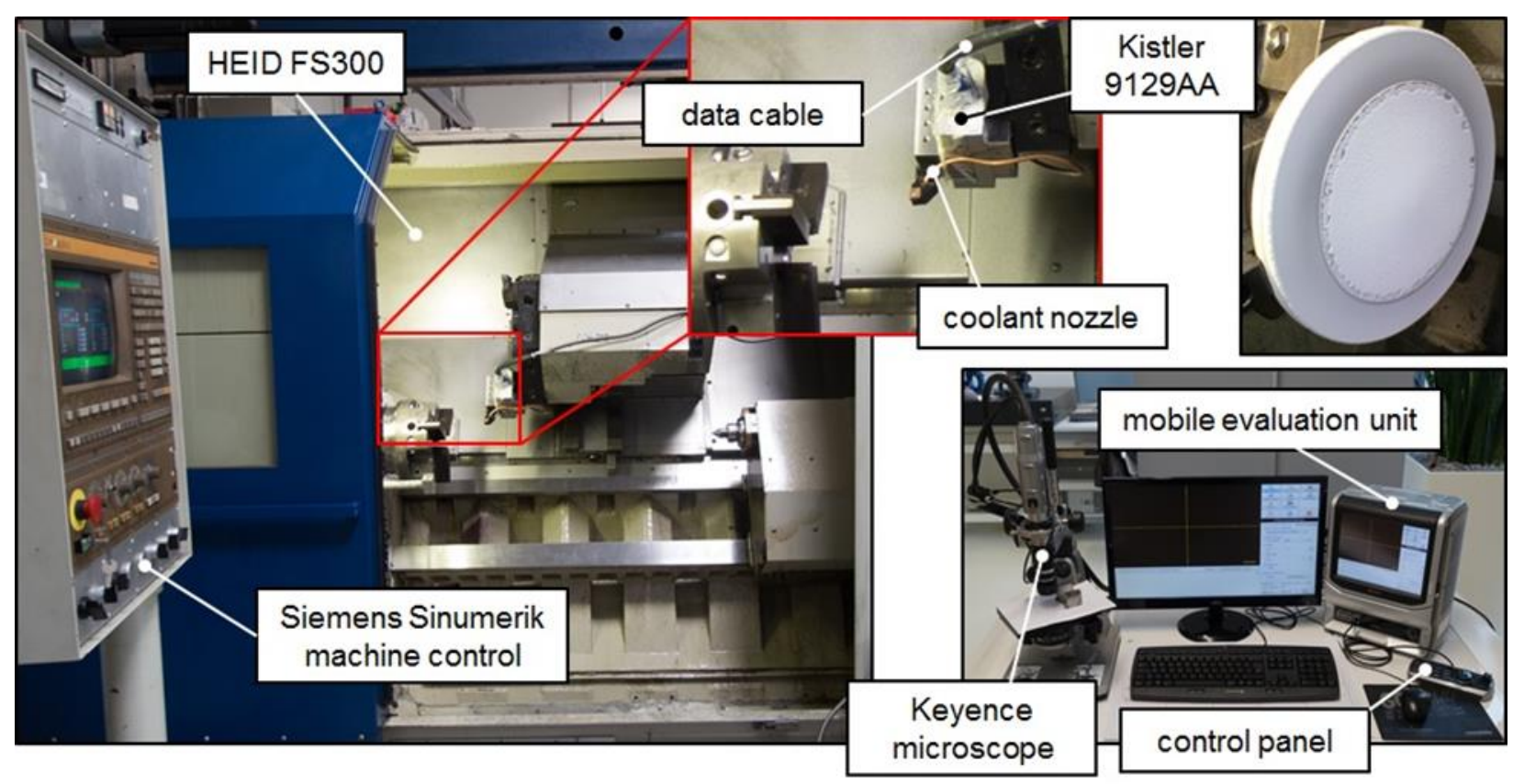

Fig. 1. Experimental setup; left: HEID FS300, downright: Keyence VW600C

Cutting inserts were delivered by Seco Tools. The geometry is a CNMG 120404 - MF1 orthorhombic insert with a rounding of the cutting edge of $50 \mu \mathrm{m}$. Two different types were used: an uncoated and one with a TiN/TiAlN multilayer coating applied by a PVD process. This cutting insert, provided by Seco Tools, was clamped inside a tool holder with the signature PCLNL2525K12JETLB. A special feature of this tool holder is the jet stream technology, which enables the transport of a cutting fluid through the shank with a pressure of up to $7 \mathrm{MPa}$. Inside it, the fluid stream is deflected to a clamping claw, which is located near the rake face of the cutting insert. Two holes lead the fluid on top of the rake face. In this investigation, the cryogenic carbon dioxide gas was passed through this tool holder. The cryogenic fluid is delivered in bottles under a compression of $6 \mathrm{MPa}$ in liquid condition. During the expansion in ambient air, a stream of cryogenic snow is built up, which consists of particles in both the solid and gas state. The clamping claw was prepared with two nozzles with an inner diameter of $2 \mathrm{~mm}$. So, the jet stream is directed and reduced on the rake face and chip. For the other experiments, a conventional cooling strategy was applied with a concentration of emulsion of $10 \%$ and minimum quantity lubrication with a fatty alcohol Blaser Vascomill MMS FA 2.

\begin{tabular}{lll}
\hline Experimental design & Setup 1 & Setup 2 \\
\hline cutting speed $\mathrm{v}_{\mathrm{c}}$ & $40 \mathrm{~m} / \mathrm{min}$ & $40 \mathrm{~m} / \mathrm{min}$ \\
feed rate $\mathrm{f}$ & $0.075 \mathrm{~mm}$ & $0.05 \mathrm{~mm}$ \\
depth of cut $\mathrm{a}_{\mathrm{p}}$ & $0.5 \mathrm{~mm}$ & $0.8 \mathrm{~mm}$ \\
cross section of the chip $\left(\mathrm{A}=\mathrm{f} \cdot \mathrm{a}_{\mathrm{p}}\right)$ & $0.038 \mathrm{~mm}^{2}$ & $0.040 \mathrm{~mm}^{2}$ \\
material removal rate & $1500 \mathrm{~mm}^{3} / \mathrm{min}$ & $1600 \mathrm{~mm}^{3} / \mathrm{min}$ \\
tool coating & uncoated \\
& multilayer coating (TiN/TiAlN) \\
cooling/lubrication strategies & conventional flood cooling \\
& minimum quantity lubrication \\
& cryogenic carbon dioxide cooling \\
\hline
\end{tabular}

Table 1. Design of Experiments

The machining process was stopped, as soon as tool wear exceeded one of three tool wear criteria as follows. Primary: tool wear land $\mathrm{VB}_{\max }$ is more than $250 \mu \mathrm{m}$, secondary: tool notch wear $\mathrm{VB}_{\text {notch }}$ exceeds $200 \mu \mathrm{m}$ and tertiary: there is a crumbling of the cutting edge, which is beyond $150 \mu \mathrm{m}$.

\section{Experimental results}

\subsection{Tool wear and cutting forces under conventional flood lubrication (CFL) and $M Q L$}

First, the machining experiments for conventional flood lubrication and minimum quantity lubrication were executed. The goal was to determine a trend for the variation of the feed rate and depth of cut, how the tool substrate 
and a coating affect the machining behavior in conjunction with the cooling strategy. Fig. 2 shows the results of the experiment. In comparison to Priarone et al. [30], the wear progression curves display a similar course. The only difference is that experiments made by Priarone et al. resulted in shorter tool life, caused by a higher cutting speed of $v_{c}=50 \mathrm{~m} / \mathrm{min}$ and feed rate of $\mathrm{f}=0.1 \mathrm{~mm}$, although the depth of cut with $a_{p}=0.3 \mathrm{~mm}$ was significantly lower. As explained in [30], the cutting speed plays an essential role during the wear progression of tools. In a short preliminary test for the experiments used for this paper, a cutting speed of $v_{c}=60 \mathrm{~m} / \mathrm{min}$ with CFL coolant was chosen. As a result, tool wear developed rapidly after a cutting time of $t_{c}=13 \mathrm{~min}$, which corresponds to an approximate cutting length of $1_{c}=800 \mathrm{~mm}$. Under conventional flood lubrication, uncoated tools led to longer tool life, whereas with minimum quantity lubrication results are contrary (see Fig. 2). In the latter case, the coating of carbide inserts extended tool life. The comparison of these two cooling or lubricating strategies revealed that flood lubrication has a more dominating effect. So, for machining $\gamma$ titanium aluminides both, cooling and lubricating, are needed. The same tendency is shown by Priarone et al. [30].

\begin{tabular}{llll|}
\hline tool: & CNMG 120404 - MF1 & cutting speed: & $\mathrm{v}_{\mathrm{c}}=40 \mathrm{~m} / \mathrm{min}$ \\
coating: & variable & feed rate: & variable \\
material: & Ti-48Al-2Cr-2Nb & depth of cut: & variable \\
\hline
\end{tabular}

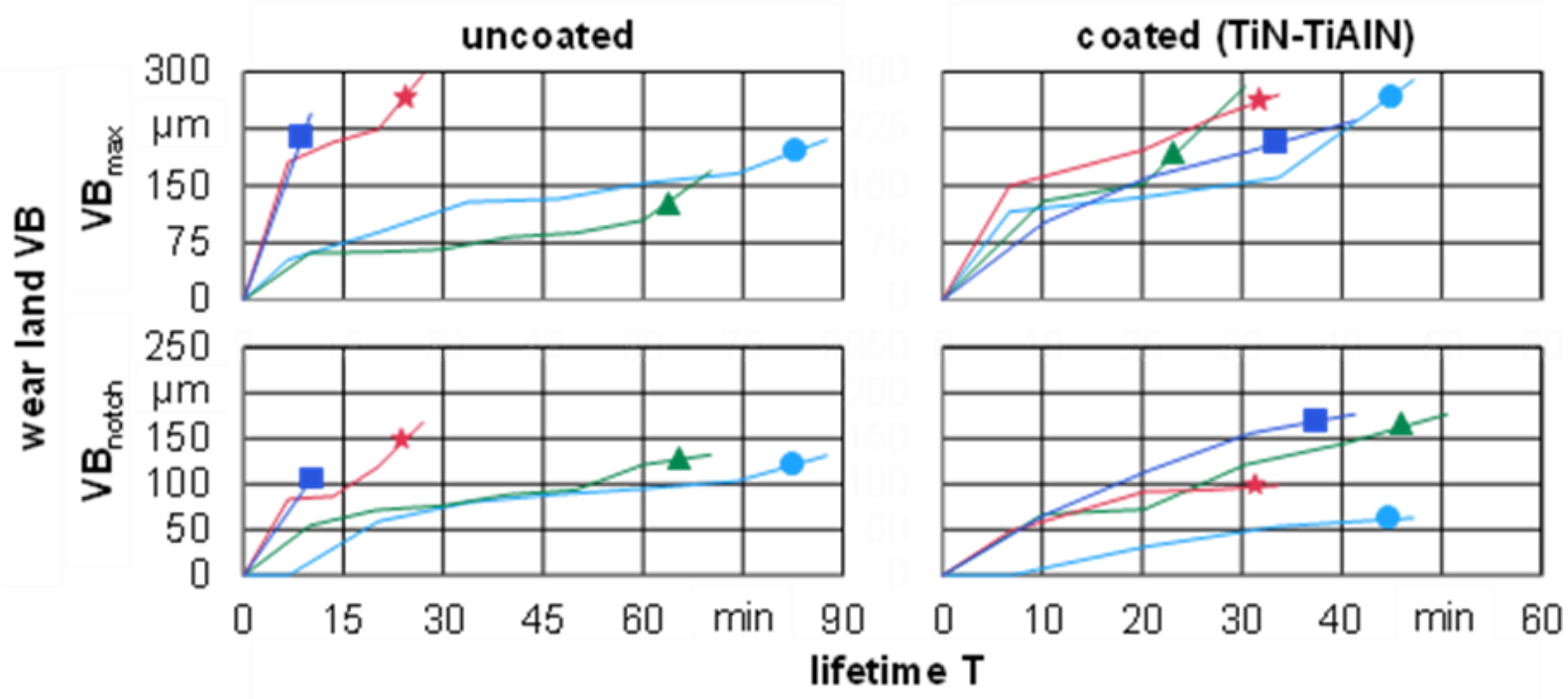

\section{CFL f0.075 $a_{p} 0.5 \rightarrow$ CFL f0.050 $a_{p} 0.8 \rightarrow$ MQLf0.075 $a_{p} 0.5 \rightarrow M Q L f 0.050 a_{p} 0.8$}

Fig. 2. Visualisation of tool-wear; experimental settings using CFL and MQL

When comparing the curves of the two experimental setups in Fig. 2, it can be seen that the setup with a higher feed rate results in a longer tool life. The similar cross section of the chips enables the comparison of the dynamic load of the tool with the cutting forces $F_{c}, F_{f}$ and $F_{p}$, with the specific cutting forces $k_{c}, k_{f}$ and $k_{p}$. Below a certain feed rate, the tool cuts off the material in the zone of the cutting edge. In cutting condition, the force angle is pointed in the direction of the workpiece and a ploughing process takes place [28]. In this situation, there is a mixture of cutting and deforming in the chip forming zone of the cutting process. This leads to a higher active force, which can be seen as the vector sum of the two force components of the feed force $F_{f}$ and cutting force $F_{c}$. The higher active force implies a higher tool load and wear development. The argument for this statement is reaffirmed, when looking at Fig. 3 (uncoated tools) and Fig. 4 (coated tools), where the cutting forces, are displayed. 


\begin{tabular}{llll|}
\hline \hline \multicolumn{4}{l}{ 26TH DAAAM INTERNATIONAL SYMPOSIUM ON INTELLIGENT MANUFACTURING AND AUTOMATION } \\
\hline \hline
\end{tabular}
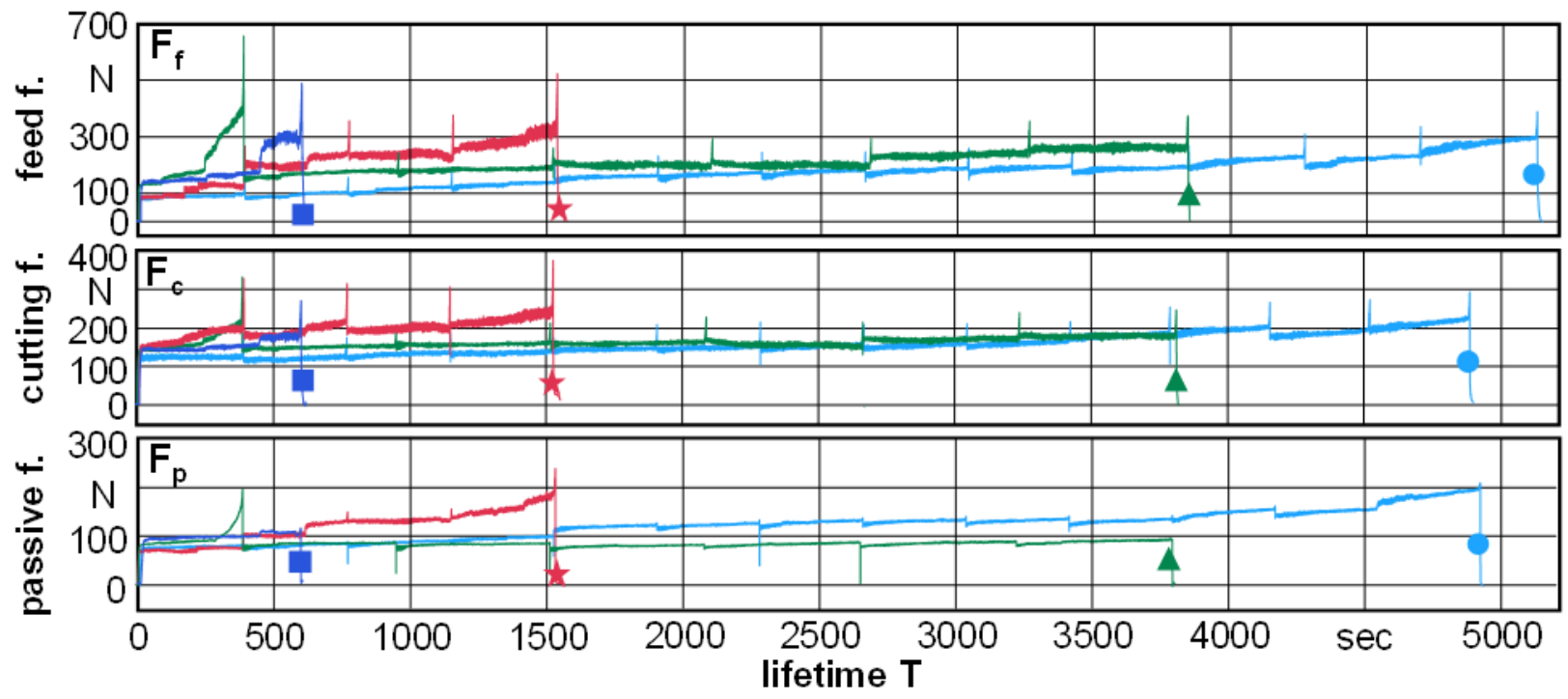

\section{$C F L$ f0.075 $a_{p} 0.5 \rightarrow C F L$ f0.050 $a_{p} 0.8 \rightarrow M Q L$ f0.075 $a_{p} 0.5 \rightarrow M Q L$ f0.050 $a_{p} 0.8$}

Fig. 3. Cutting forces measured during machining with uncoated carbide inserts

It can be seen, when comparing the two curves of the feed force and the cutting force during the machining with conventional flood lubricating, that the higher feed rate of $\mathrm{f}=0.075 \mathrm{~mm}$ has smaller feed and cutting forces than the lower feed rate of $\mathrm{f}=0.05 \mathrm{~mm}$. For machining with minimum quantity lubrication, the same trend can be observed.

\begin{tabular}{llll|}
\hline tool: & CNMG 120404 - MF1 & cutting speed: & $v_{\mathrm{C}}=40 \mathrm{~m} / \mathrm{min}$ \\
coating: & TiN-TiAIN & feed rate: & variiert \\
material: & Ti-48Al-2Cr-2Nb & depth of cut: & variiert \\
\hline
\end{tabular}

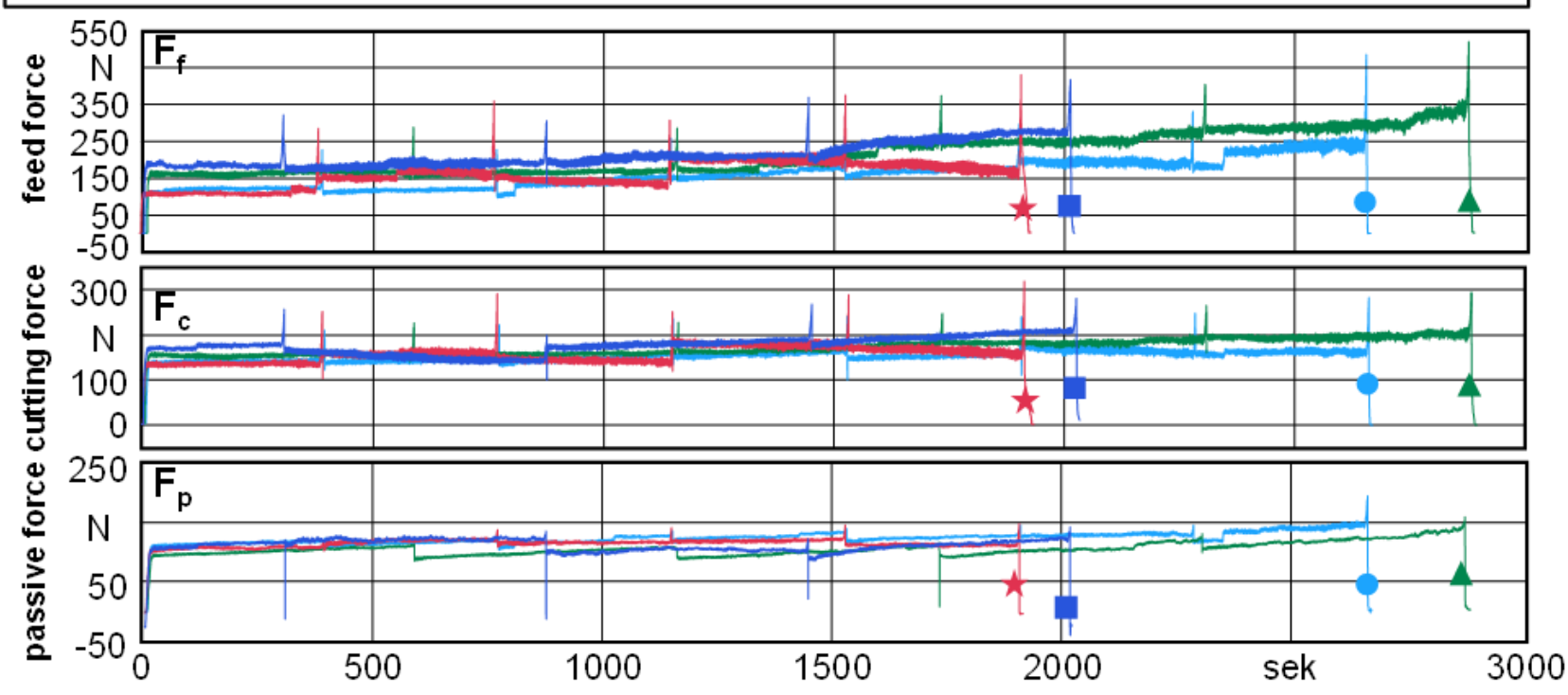

CFL f0.075 $a_{p} 0.5 \rightarrow$ CFL f0.050 $a_{p} 0.8 \star M Q L$ f0.075 $a_{p} 0.5 \rightarrow$ MQL f0.050 $a_{p} 0.8$

Fig. 4. Cutting forces measured during machining with coated carbide inserts 


\subsection{Material removal rate and cutting volume}

In chapter 3.1 the influence of tool wear and cutting forces were discussed. Another interesting fact, explained in this chapter, is the material removal rate and the cutting volume. Because of the targeted variation of the feed rate and the depth of cut, nearly similar cross section of the chips, and consequently the same material removal rates were achieved (see Error! Reference source not found.). The removal rates differ only by $100 \mathrm{~mm} 3 / \mathrm{min}$. When taking a closer look at Fig. 5, a significant influence on cutting volumes, achieved by the two different cooling strategies, can be observed. In conjunction with Fig. 2 it can be seen, that cutting volumes differ in a significant way. The reason is that some cutting inserts were not stopped at the wear criteria, showing artificially longer tool life times, caused by the nature of the experiments.

The results of the cutting volumes vary between 10 to $20 \%$. When applying minimum quantity lubrication, only the uncoated tool has an insignificant difference between the two parameter settings. The reason is that the tools wore out rapidly experiencing only a short life time, which is insufficient to compensate the difference in the value of the material removal rate.

\begin{tabular}{|llll|}
\hline tool: & CNMG 120404 - MF1 & cutting speed: & $\mathrm{v}_{\mathrm{c}}=40 \mathrm{~m} / \mathrm{min}$ \\
coating: & variable & feed rate: & variable \\
material: & Ti-48Al-2Cr-2Nb & depth of cut: & variable \\
\hline
\end{tabular}

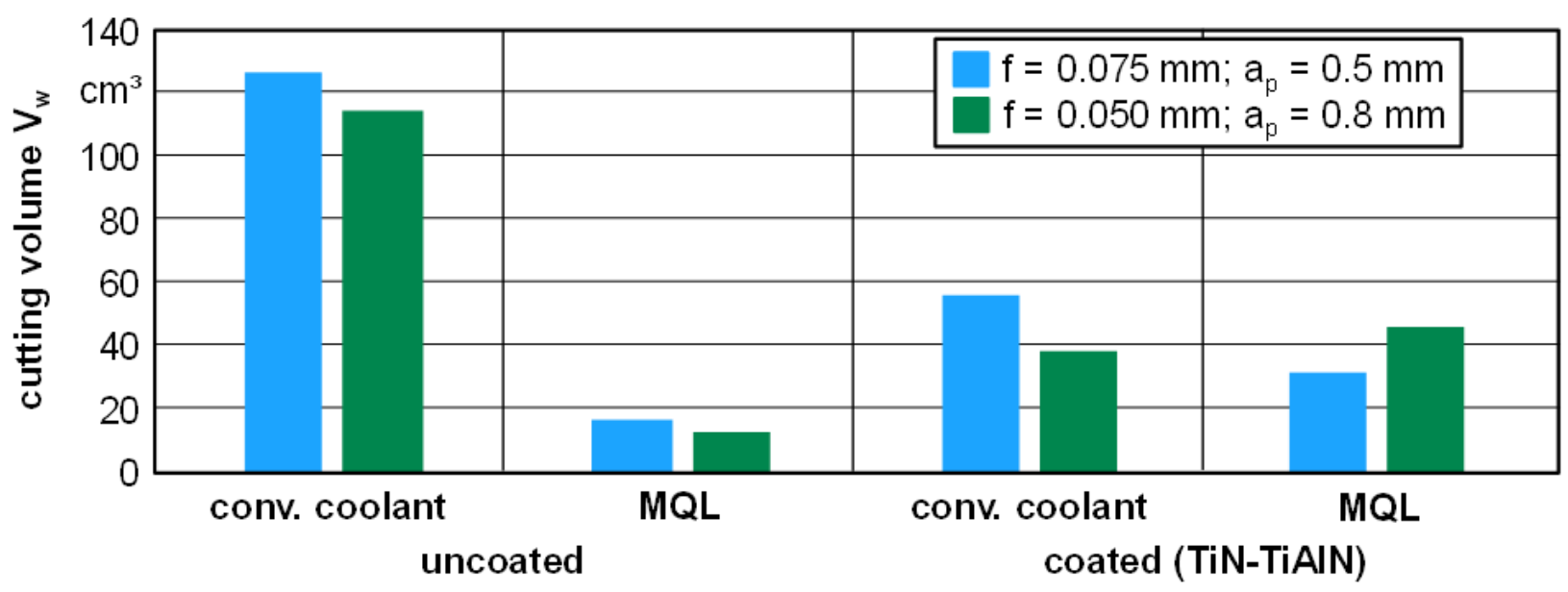

Fig. 5. Cutting volumes resulted from experiment

The consideration of the cutting volume enables an evaluation independently from the feed velocity. It should be validated, if the carbon dioxide cooling strategy can achieve an increase in tool life of $\gamma$ titanium aluminides, like it is when machining of titanium alloys [31].

\subsection{The cryogenic carbon dioxide cooling}

Especially in machining of difficult-to-cut titanium alloys, like $\alpha-,(\alpha+\beta)$ - and $\beta$-alloys, the cooling method with a cryogenic gas led to good results with respect to tool wear. These results are verified by the fact that there is a higher demand for cooling than for lubrication in machining of titanium alloys. Klocke et al. [24] investigated a third generation $\gamma$ titanium aluminide while machining it with a cryogenic liquid nitrogen $\left(\mathrm{LN}_{2}\right)$ cooling strategy. In comparison to dry machining of titanium aluminides, the liquid nitrogen cooling decreased the tool-wear significantly during the starting phase of the process [6]. In comparison, a cooling temperature of $-195^{\circ} \mathrm{C}$ is realized by using liquid nitrogen, whereas carbon dioxide can reach a cooling temperature of $-60^{\circ} \mathrm{C}$. In Fig. 6, the tool wear, after the first cutting path, by applying the cryogenic carbon dioxide cooling and the conventional flood lubrication is shown.

In the starting phase of the cryogenic carbon dioxide cooled machining process it can be observed that the tungsten carbide inserts tend to a significant notch wear, caused by the freezing process. The tool material is cooled in a very strong way, retaining its whole strength and hardness properties, yet causing the material to get slightly brittle. When the workpiece material is cut during the machining process, it hits the tool material and pulls out some material from the tool. The discontinuous process near the workpiece entrance initiates this high loading of the tool. 


\begin{tabular}{|c|c|c|c|}
\hline $\begin{array}{l}\text { tool: } \\
\text { coating: } \\
\text { material: } \\
\text { cutting length: }\end{array}$ & $\begin{array}{l}\text { CNMG } 120404 \text { - MF1 } \\
\text { variable } \\
\text { Ti-48Al-2Cr-2Nb } \\
\text { variable }\end{array}$ & $\begin{array}{l}\text { cutting speed: } \\
\text { feed rate: } \\
\text { depth of cut: } \\
\text { cooling method: }\end{array}$ & $\begin{array}{l}\mathrm{v}_{\mathrm{c}}=40 \mathrm{~m} / \mathrm{min} \\
\text { variable } \\
\text { variable } \\
\text { variable }\end{array}$ \\
\hline
\end{tabular}

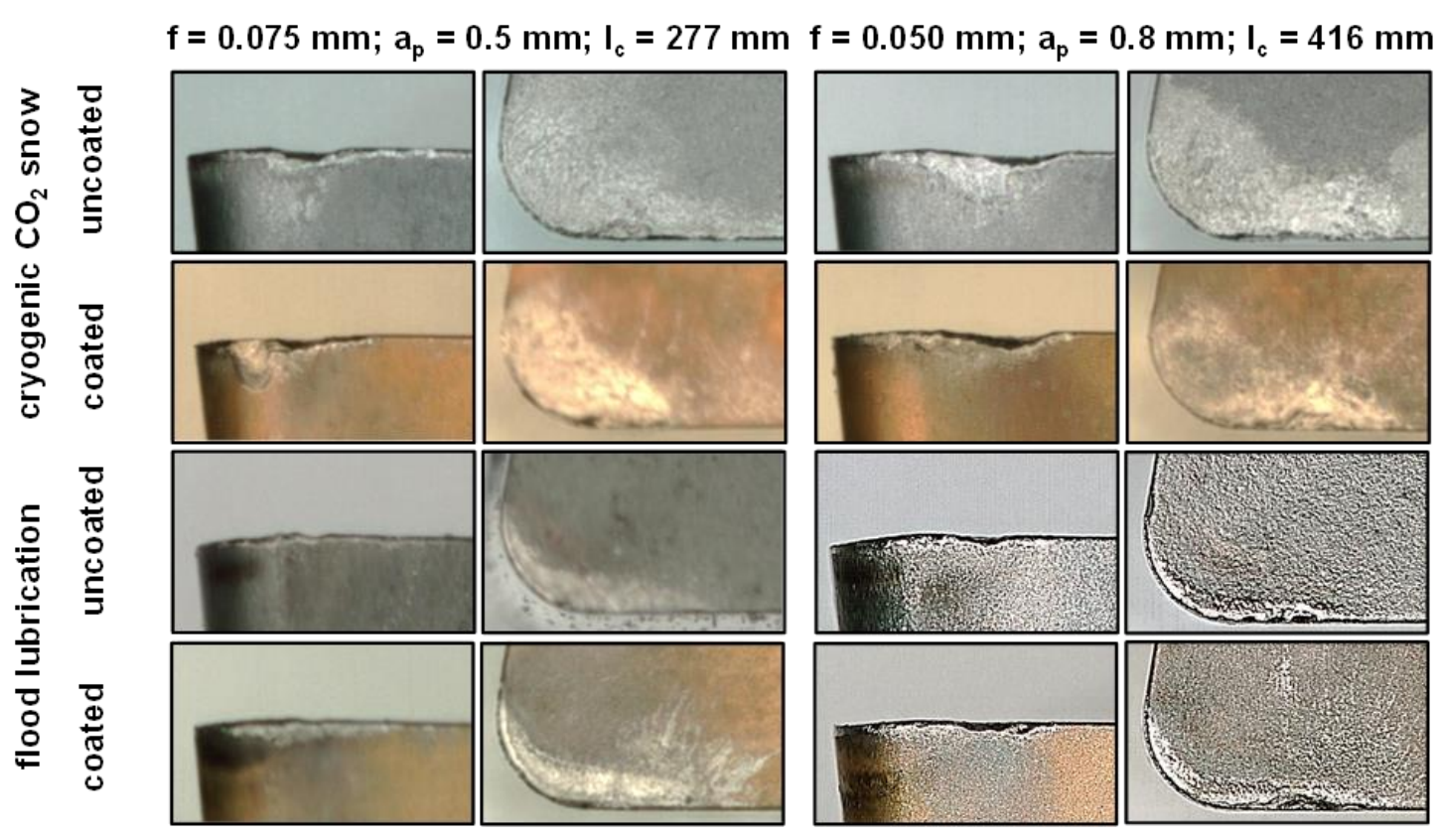

Fig. 6. Comparison of the tool-wear on the rake face and flank face of the cutting insert

Another effect of the carbon dioxide cooling is the strong freezing of the surrounding of the tool. In order to measure the cutting forces, a dynamometer was located next to the tool. The curves of the cutting forces are shown in Fig. 7. When observing the curve of the cutting force $F_{c}$, a big drift at the end of every single cutting path can be seen. This is caused by the freezing of the piezocrystals inside the dynamometer. In this situation the correct electric charge cannot be measured, resulting in false cutting forces.

In chapter 3.1 it was pointed out, that a higher feed rate implicates lower active forces $\mathrm{F}_{\mathrm{a}}$. This fact can be verified also in Fig. 7.

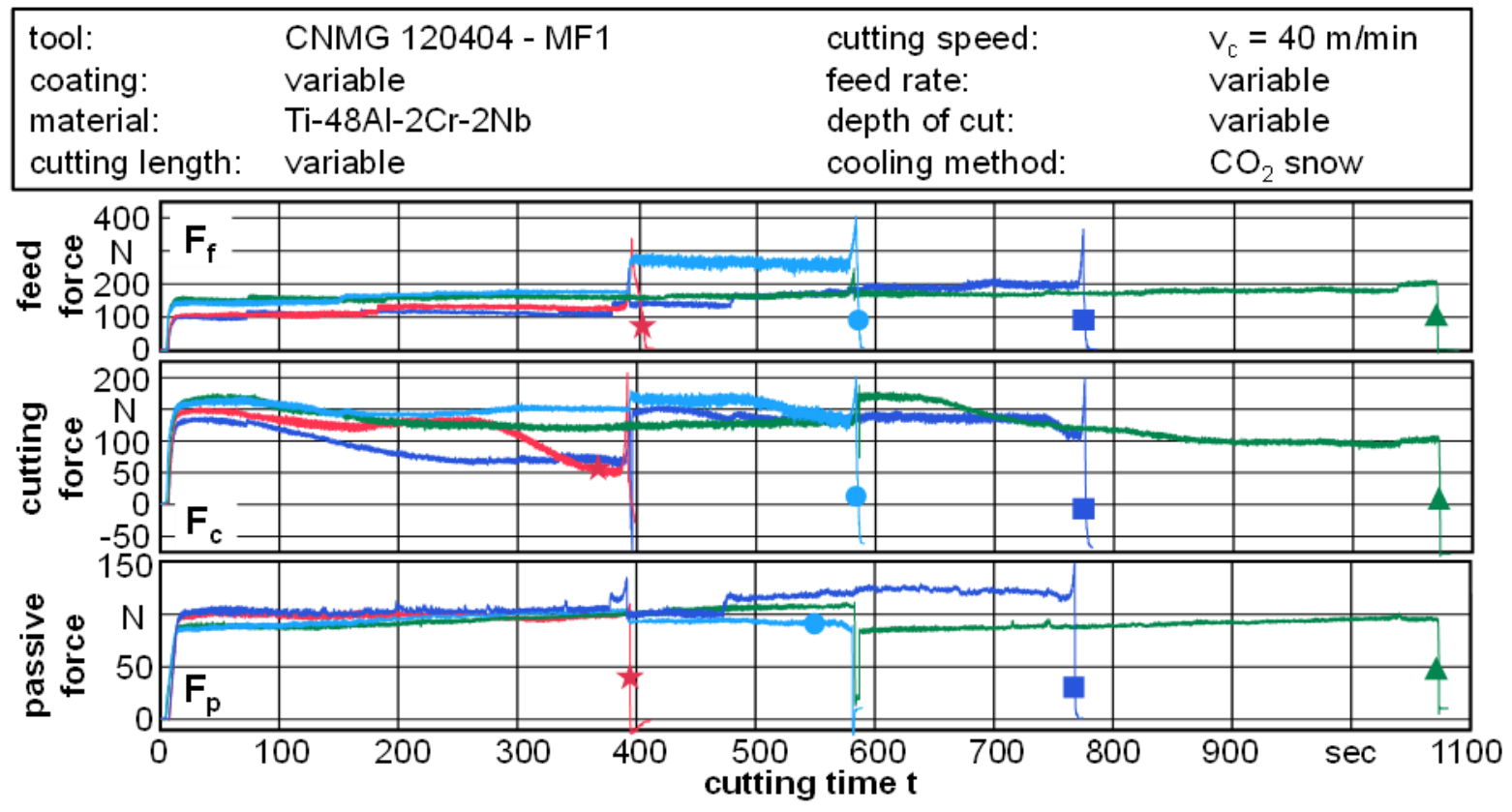

$\mathrm{f} 0,050 \mathrm{a}_{\mathrm{p}} 0,8$ uncoat. $\rightarrow \mathrm{f} 0,050 \mathrm{a}_{\mathrm{p}} 0,8$ coated $\rightarrow \mathrm{fO}, 075 \mathrm{a}_{\mathrm{p}} 0,5$ uncoat. $-\mathrm{fo}, 075 \mathrm{a}_{\mathrm{p}} 0,5$ coated

Fig. 7. Cutting forces measured during machining with cryogenic carbon dioxide cooling 


\section{Conclusion}

The problem examined in the paper is to study the effect between feed rate and depth of cut during machining the $\gamma$ titanium aluminide Ti-48Al-2Cr-2Nb by applying different cooling strategies. To obtain basic knowledge, the machining technology of turning was chosen. It was shown, that there is a significant influence on tool wear induced by an increase of the depth of cut and a decrease of the feed rate. In the following list, the important results of the investigation are summarized:

- In conventional flood lubrication uncoated tools experience a longer tool life

- In minimum quantity lubrication (MQL) tool coating prolongs tool life

- A lower feed rate leads to a cutting off material in the cutting zone of the cutting edge and initiates a ploughing process

- The cryogenic carbon dioxide gas leads to a faster notch wear

- $\mathrm{CO}_{2}$ cools down the surrounding of the tool in such a strong way that the dynamometer is experiencing difficulties in measuring the cutting forces [29]

In future works, a smaller nozzle to decrease the flow stream of the carbon dioxide gas should be constructed increasing the service time of the bottle of the carbon dioxide and making the whole process more effective. In this case, the machining experiment with the cryogenic carbon dioxide cooling could be retried in such a way, that the cutting tool is used until it reaches the wear criterion. This would enable to verify, whether the excessive notch wear takes place only in the starting phase of the machining process and stabilizes until the tool wear criteria are reached.

\section{References}

[1] H. Clemens, S. Mayer, Intermetallisches Titanaluminid - Ein innovativer Leichtbauwerkstoff für Hochtemperaturanwendungen, BHM 156 (2011) 255-260.

[2] B. Heine, Nickelbasis-Superlegierungen für Flugzeugantriebe aus metallkundlicher Sicht, WOMag 1 (2014) 1-8.

[3] A.L. Mantle, D.K. Aspinwall, Surface integrity and fatigue life of turned gamma titanium aluminide, J. Mat. Proc. Techn. 72 (1997) 413-420.

[4] F. Appel, M. Oehring, R. Wagner, Novel design concepts for gamma-base titanium aluminide alloys, Intermetallics 8 (2000) 1283-1312.

[5] M. Hadi, M. Mahmood, A. Shafyei, The effect of lanthanum on the microstructure and high temperature mechanical properties of a beta-solidifying TiAl alloy, Journal of Alloys and Compounds 618 (2015) 27-32.

[6] N. Eliaz, G. Shemesh, R.M. Latanision, Hot corrosion in gas turbine components, Eng. Fail. Analysis 9 (2002) 31 43.

[7] E.O. Ezugwu, Z.M. Wang, A.R. Machado, The machinability of nickel-based alloys, J. Mat. Proc. Techn. 86 (1999) 1-16.

[8] S. Kolahdouz, M. Hadi, B. Aezoo, S. Zamann, Investigation of surface integrity in high speed milling of gamma titanium aluminide under dry and minimum quantity lubricant conditions, Procedia CIRP 26 (2015) 367-372.

[9] M. Rahman, Y.S. Wong, A.R. Zareena, Machinability of titanium alloys, JSME Series C 46 (2003) 107-115.

[10] R. M'Saoubi, J.C. Outeiro, H. Chandrasekaran, O.W. Dillon Jr., I.S. Jawahir, A review of surface integrity in machining and its impact on functional performance and life of machined products, Int. J. Sustainable Manufacturing Vol. 1 1 1/2 (2008) 203-236.

[11] P. Priarone, F. Klocke, M.G. Faga, D. Lung, L. Settineri, Tool life and surface integrity when turning titanium aluminides with PCD tools under conventional wet cutting and cryogenic cooling, Int. J. Adv. Manuf. Techn. (2015) 1-10.

[12] D. Ulutan, T. Ozel, Machining induced surface integrity in titanium and nickel alloys: A review, Int. J. of Machine Tools \& Manufacture 51 (2011) 250-280.

[13] A.E.I. Elshwain, N. Redzuan, N.M. Yusof, Machinability of nickel and titanium alloys under gas-based coolantlubricants (CLS) - A Review, Int. J. Research in Engineering and Technology 2 (2013) 690-702.

[14] R.B. da Silva, A.R. Machado, E.O. Ezugwu, J. Bonney, W.F. Sales, Tool life and wear mechanisms in high speed machining of Ti-6Al-4V alloy with PCD tools under various coolant pressures, J. Mat. Proc. Techn. 213 (2013) 1459-1464.

[15] D. Zhu, X. Zhang, H. Ding, Tool wear characteristics in machining of nickel-based superalloys, Int. J. of Machine Tools \& Manufacture 64 (2013) 60-77.

[16] D.K. Aspinwall, R.C. Dewes, A.L. Mantle, The machining of $\gamma$-TiAl intermetallic alloys, CIRP Annals Manufacturing Technology 54 (2005) 99-104.

[17] R.G. Pérez, Wear mechanisms of WC inserts in face milling of gamma titanium aluminides, Wear 259 (2005) 1160-1167.

[18] F. Klocke, L. Settineri, D- Lung, P.C. priarone, M. Arft, High performance cutting of gamma titanium aluminides: Influence of lubricoolant strategy on tool wear and surface integrity, Wear 302 (2013) 1136-1144. 
[19] L. Zhu, C. Chen, B. Viehweger, Experimental Study on Deep Hole Drilling Gamma Titanium Aluminide, Key Engineering Materials 455 (2011) 293-296.

[20] P.C. Priarone, S. Ruffa, J.S. Bedolla, L. Settineri, A DoE approach to hole quality evaluation in drilling of an electron beam melted titanium aluminide, Procedia CIRP 8 (2013) 481-486.

[21] A.L. Mantle, D.K. Aspinwall, Surface integrity of a high speed milled gamma titanium aluminide, J. Mat. Proc. Techn. 118 (2001) 143-150.

[22] A.R.C. Sharman, D.K. Aspinwall, R.C. Dewes, P. Bowen, Workpiece surface integrity considerations when finish turning gamma titanium aluminide, Wear 249 (2001) 473-481.

[23] R. Hood, D.K. Aspinwall, C. Sage, W.Voice, High speed ball nose end millng of $\gamma$-TiAl alloys, Intermetallics 32 (2013) 284-291.

[24] F. Klocke, D. Lung, M. Arft, P. Priarone, L. Settineri, On high-speed turning of a third generation gamma titanium aluminide, Int J Adv Manuf Technol 65 (2013) 155-163.

[25] Y.F. Ge, Y.C. Fu, J.H. Xu, Experimental Study on High Speed Milling of $\gamma$-TiAl Alloy, Key Engineering Materials 339 (2007) 6-10.

[26] L. Settineri, P. Priarone, M. Arft, D. Lung, T.Stoyanov, An evaluative approach to correlate machinability, microstructures, and material properties of gamma titanium aluminides, CIRP Annals 63 (2014) 57-60.

[27] P. Priarone, M. Robiglio, L. Settineri, V. Tebaldo, Effectiveness of minimizing cutting fluid use when turning difficult-to-cut alloys, Procedia CIRP 29 (2015) 341-346.

[28] P. Albrecht, New Developments in the Theory of the Metal-Cutting Process Part 1, J. Engineering for Industry 82 (1960) 348-357.

[29] Kistler AG, Data sheet Type 9129AA

[30] P. Priarone, M. Robiglio, L. Settineri, V. Tebaldo, Milling and turning of titanium aluminides by using minimum quantity lubrication, Procedia CIRP 24 (2014) 62-67.

[31] C. Machai, D. Biermann, Machining of $\beta$-titanium-alloy Ti-10Fe-2Fe-3Al under cryogenic conditions: Cooling with carbon dioxide snow, Journal of Materials Processing Technology 211 (2011) 1175-1183. 